\title{
Immunohistochemical evaluation of phosphorylated SMAD2/SMAD3 and the co-activator P300 in human glomerulonephritis: correlation with renal injury
}

\author{
Theodoros I. Kassimatis a, b, *, Ioanna Giannopoulou c, Dimitra Koumoundourou a, \\ Emily Theodorakopoulou d, Ioannis Varakis a, Lydia Nakopoulou c \\ a Department of Anatomy and Histology-Embryology, Medical School, University of Patras, Patras, Greece \\ ${ }^{b}$ Department of Nephrology, "Evangelismos" General Hospital, Athens, Greece \\ c $2^{\text {nd }}$ Pathology Department, "Atticon" University Hospital, Athens, Greece \\ ${ }^{d}$ Division of Internal Medicine, Patras University Hospital, Patras, Greece
}

Received: April 4, 2006; Accepted: September 11, 2006

\begin{abstract}
Background: Smad 2 and Smad3 are transcription factors that mediate transforming growth factor beta (TGF- $\beta$ ) signals. Upon their activation, phosphorylated Smad2/Smad3 (pSmad2/Smad3), translocate to the nucleus and associate with co-activators such as p300, regulating the transcription of genes that contribute to the fibrotic processes. Methods: We investigated the immunohistochemical expression of pSmad2/Smad3 and the co-activator p300 in 152 renal biopsy specimens from patients with various types of glomerulonephritides (GNs) and in 15 normal kidney specimens. Patients' clinical data (serum creatinine levels and proteinuria) had been collected. Results: There was a dramatic increase in the expression of pSmad2/3 and p300 in all glomerular cell types in all GNs. $\mathrm{pSmad} 2 / 3$ expression was increased in all tubular segments (except for the proximal tubules in nonproliferative GNs), while p300 expression was significantly increased only in the proximal tubular cells in all GNs. Glomerular and tubular pSmad2/Smad3 and p300 were significantly increased in proliferative GNs (compared to the nonproliferative), particularly in the secondary group. The expression profile of $\mathrm{p} 300$ correlated positively with the expression of $\mathrm{pSmad} 2 / \mathrm{Smad} 3$ in the diseased glomeruli and proximal tubules. pSmad2/3 and p300 were very often detected in segmental hyperplastic lesions, cellular crescents, microadhesions and segmental or global sclerotic areas. Glomerular and proximal tubular $\mathrm{pSmad} 2 / \mathrm{Smad} 3$ was positively correlated with serum creatinine levels, while distal and collecting tubular pSmad2/3 and p300 correlated positively with tubular atrophy. Glomerular and proximal tubular pSmad2/3 expression and glomerular p300 expression correlated positively with lupus nephritis activity. Conclusion: Our results suggest that pSmad2/3-p300 pathway may play a pivotal role in the pathogenesis and progression of human glomerulonephritis.
\end{abstract}

Keywords: glomerulonephritis $\bullet$ pSmad2/3 - p300 • renal fibrosis

\section{Introduction}

The Smad pathway is the best characterized signaling pathway employed by transforming growth fac-

\footnotetext{
* Correspondence to: Theodoros KASSIMATIS MD

Department of Nephrology, "Evangelismos" General Hospital Athens, Greece.

Tel.: +302107201629

Fax: +302107201624

E-mail: theokas@med.upatras.gr
}

tor- $\beta$ (TGF- $\beta$ ). TGF- $\beta$ is a multifunctional growth factor involved in the regulation of cell proliferation, differentiation, extracellular matrix (ECM) formation and immune response $[1,2]$. TGF- $\beta$ has been proposed to mediate glomerulosclerosis and interstitial fibrosis in various renal diseases including glomerulonephritis [3-5]. TGF- $\beta$ is overexpressed in human glomerular diseases including 
immunoglobulin A (IgA) nephropathy, lupus nephritis, focal and segmental glomerulosclerosis [6].

TGF- $\beta$ binds to three different types of serine/threonine kinase receptors [7]. Upon TGF- $\beta$ binding, the constitutively active TGF- $\beta$ type II receptor associates with and phosphorylates the type I receptor [8]. The type I receptor kinase then phosphorylates the Smad2 and Smad3 proteins [9, 10]. The phosphorylated $\mathrm{Smad} 2 / 3$ form heteromeric complexes with Smad4 and translocate into the nucleus, $[9,11-15]$. Smad3 and Smad4 interactions with DNA are weak and insufficient to convey promoter selectivity [16]. On the other hand, despite being highly homologous with $\mathrm{Smad} 3, \operatorname{Smad} 2$ is unable to bind to DNA directly. Thus, pSmad2/3Smad4 complexes require other transcription factors and co-activators or co-repressors to target them to specific sequences. p300 is a transcriptional co-activator that appears to be involved in the transcriptional activation of Smad complexes [17]. It possesses histone acetyl transferase activity, suggesting that transcriptional activation by Smad complexes may require altering nucleosome structure and remodeling of the chromatin $[18,19]$.

Increased staining for Smad3 [20] has been described in the glomeruli of $d b / d b$ mice, a genetic model of type 2 diabetes. Moreover, increased expression of $\mathrm{pSmad} 2 / 3$ has been reported in the glomerular epithelial cells of the sclerotic segments in renal biopsies from patients with focal and segmental glomerulosclerosis [21]. Earlier work demonstrated that Smads 2 and 3 can recruit the p300 co-activator to activate transcription [15]. Similarly, interaction of Smad4 with p300 has been reported [16]. Previous studies have also demonstrated that Smad4 contains an intrinsic 48-aminoacid p300 dependent SAD (Smad activation domain) [17]. Moreover, p300 may be involved in TGF- $\beta 1 /$ Smad-pathway-mediated type I collagen gene transcription in mouse mesangial cells [22]. However, no data exist on the expression patterns of p300 and phosphorylated Smads in human glomerulonephritis (GN).

Recent studies have demonstrated that Smad signaling is also a critical pathway for renal fibrosis induced by other pro-fibrotic factors, such as angiotensin II and advanced glycation end products (AGE) [23]. These pro-fibrotic factors can activate Smads directly and independently of TGF$\beta$. They can also cause renal fibrosis via the
ERK/p38 MAP kinase-Smad signaling cross-talk pathway. Results from these studies demonstrate that Smad signaling is probably a key and final common pathway of renal fibrosis [23].

In an effort to extend previous knowledge on the activation of Smad signalling pathway in diseased human kidneys we investigated the expression of pSmad2/3 and p300 using immunohistochemical methods, in serial sections of a wide range of glomerulonephritides. We localised the expression of these molecules to several pathologic lesions. Correlations were performed between the expression profile of these molecules with clinical parameters of renal function and histologic injury.

\section{Material and methods}

\section{Patients}

Percutaneous renal biopsies were obtained from 152 patients with various types of GN. Renal biopsies were performed for diagnostic purposes and informed consent for the use of renal biopsy tissue, in excess of that required for diagnostic purposes, was obtained from the patients. 86 patients had primary GN and 66 patients secondary GN. Apart from taking into account the primary or the secondary nature of the glomerular disorder, GNs were further divided into proliferative ( $\mathrm{n}$ $=85)$ and nonproliferative $(\mathrm{n}=67)$. The non-proliferative group of primary GNs included minimal change glomerular disease (MCD, $\mathrm{n}=10$ ), membranous GN (MGN, $\mathrm{n}=23$ ), focal segmental glomerulosclerosis (FSGS, $\mathrm{n}=16$ ), while the respective group in SLE GNs consisted of cases with mesangial changes (WHO class II, $\mathrm{n}=10$ ) and diffuse membranous GNs (WHO class $\mathrm{V}, \mathrm{n}=8$ ). The proliferative group of primary GNs included acute diffuse proliferative GN [in detail, acute post-infectious GN (PI, $n=6$ ), membranoproliferative GN (MPGN, $n=7)]$ and IgA nephropathy $(\mathrm{n}=$ 24 ), while the proliferative group of secondary GNs comprised those pauci-immune GN due to vasculitis (Pauci-Im GN, $n=23$ ) as well as focal segmental SLE GN (WHO class III, $\mathrm{n}=9$ ) and diffuse proliferative SLE GN (WHO class IV, $\mathrm{n}=16$ ). The classification and clinical parameters of patients with GN are given in Table 1. As a control group, totally normal kidney sections from 15 kidneys resected for renal cell carcinoma were examined. 
Table 1 Classification and clinical parameters of patients with glomerulonephritis

\begin{tabular}{|c|c|c|c|c|c|c|}
\hline \multicolumn{2}{|l|}{ Disease } & No. of patients & Age (Years) & $\begin{array}{l}\text { Gender } \\
\text { (\% male) }\end{array}$ & $\begin{array}{c}\text { Serum } \\
\text { Creatinine } \\
(\mathrm{mg} / \mathrm{dL})\end{array}$ & $\begin{array}{c}24-H o u r \\
\text { Urinary } \\
\text { Protein }(\mathrm{g} / \mathrm{d})\end{array}$ \\
\hline \multirow{3}{*}{$\begin{array}{c}\text { Non-proliferative pri- } \\
\text { mary GNs }\end{array}$} & MCD & 10 & $39.5 \pm 19.6$ & 90 & $0.92 \pm 0.12$ & $5.7 \pm 3.1$ \\
\hline & FSGS & 16 & $36.5 \pm 14.7$ & 69 & $1.21 \pm 0.58$ & $3.3 \pm 3.35$ \\
\hline & MGN & 23 & $59.2 \pm 16.3$ & 61 & $1.28 \pm 0.86$ & $6.16 \pm 6.1$ \\
\hline \multirow{3}{*}{$\begin{array}{c}\text { Proliferative primary } \\
\text { GNs }\end{array}$} & $\operatorname{Ig} \mathrm{A}$ & 24 & $33.5 \pm 13.9$ & 71 & $0.96 \pm 0.38$ & $1.74 \pm 1.67$ \\
\hline & MPGN & 7 & $41.6 \pm 28.2$ & 14 & $1.65 \pm 0.20$ & $6.34 \pm 5.3$ \\
\hline & PostIn GN & 6 & $40.6 \pm 25.1$ & 84 & $3.95 \pm 2.19$ & $3.35 \pm 0.91$ \\
\hline $\begin{array}{c}\text { Non-proliferative sec- } \\
\text { ondary GNs }\end{array}$ & NPLN & 18 & $38.7 \pm 11.1$ & 17 & $1.33 \pm 0.82$ & $1.68 \pm 2.15$ \\
\hline \multirow{2}{*}{$\begin{array}{l}\text { Proliferative sec- } \\
\text { ondary GNs }\end{array}$} & PLN & 25 & $34 \pm 9.4$ & 12 & $1.37 \pm 0.71$ & $3.27 \pm 2.6$ \\
\hline & Pauci-Im GN & 23 & $52.2 \pm 19.6$ & 52 & $3.69 \pm 2.26$ & $0.91 \pm 0.97$ \\
\hline
\end{tabular}

MCD, minimal change disease; FSGS, focal segmental glomerulosclerosis; MGN, membranous GN; IgA, IgA nephropathy; MPGN, membranoproliferative GN; PostIn, postinfectious GN; NPLN, nonproliferative lupus nephritis (SLE II/V); PLN, proliferative lupus nephritis (SLE III/IV); and Pauci-Im GN, pauci-immune GN. Data are presented as mean \pm 1 standard deviation. NOTE: To convert serum creatinine in $\mathrm{mg} / \mathrm{dL}$ to $\mu \mathrm{mol} / \mathrm{L}$ multiply by 88.4 .

\section{Immunohistochemistry}

Immunohistochemical staining was performed on $4 \mu \mathrm{m}$ thick formalin-fixed paraffin embedded sections, using a biotin free, two-step, HRP-labelled detection system (DACO EnVision ${ }^{\mathrm{TM}}$ ). Sections were deparafinized in xylene and rehydrated through graded alcohols. After quenching of endogenous peroxidase activity using a methanol/hydrogen peroxide solution $(0.3 \%$ in TBS for $30 \mathrm{~min}$ ), we proceeded to microwave heat-mediated antigen retrieval in $10 \mathrm{mM}, \mathrm{pH}=6$ citrate buffer and blockage of nonspecific binding by incubation in $10 \%$ normal horse serum in TBS (Vector Lab, Burlingame, CA, USA) for $30 \mathrm{~min}$ at room temperature. Subsequently, sections were incubated for 40 minutes at $4{ }^{\circ} \mathrm{C}$ with the primary antibodies. The primary antibodies used in our study were: (1) anti-pSmad2/3 rabbit polyclonal antibody (\#3101) (Cell Signaling Technology Inc, USA) at a dilu- tion 1:500 and (2) anti-p300 rabbit polyclonal antibody (sc-585) (Santa Cruz Biothechnology Inc, UK) at a dilution 1:500. Sections were then incubated with a biotin free, two-step, HRP-labelled detection system (DACO EnVisionTM) for $30 \mathrm{~min}$ at room temperature followed by the addition of 3,3'-diaminobenzidine tetrachlorohydrate (DAB), in order to achieve visualization of the requested antigens. The biotin-avidin/streptavidin system is often used as an amplification step to increase sensitivity. However, in some tissues such as kidney, "nonspecific" interactions may be a problem due to high levels of endogenous biotin-containing proteins [24]. Thus, a biotin free detection system was used in our experiments. Finally, sections were rinsed, counterstained with hematoxylin and mounted. In cases where the identification of proximal versus distal tubules was difficult, consecutive serial sections were stained so that any remnants of brush border became detectable. Previously pSmad2/3 or p300 
positive breast cancer tissue sections served as positive controls in each staining procedure while negative controls included substitution of primary antibody with nonimmune mouse IgG diluted at the same concentration for each antibody, or the omission of primary antibodies.

\section{Quantification of pSmad2/3 and p300 immunostaining in human renal biopsies}

Serial sections were immunostained for each molecule. Nonglobally sclerosed glomeruli (mean, $15 \pm 4.3$; range 10 to 25 ) were counted. The intensity of glomerular staining of $\mathrm{pSmad} 2 / 3$ and $\mathrm{p} 300$ was evaluated according to the following 0 to 3 scale: $\mathbf{0},<10 \%$ cells with nuclear staining; 1, weak nuclear staining intensity or $11-50 \%$ of cells with nuclear staining; 2 , moderate nuclear staining intensity and $>50 \%$ of cells with nuclear staining and 3, strong nuclear staining intensity and $>50 \%$ of cells with nuclear staining. The staining status of glomerular lesions was also assessed, with immunopositivity being recorded when some degree of immunostaining was noticeable. When no staining was observed, the respective lesions were characterized as negative. The staining intensity of the different parts of the tubules was evaluated according to the following: $\mathbf{0},<10 \%$ cells with nuclear staining; 1, weak nuclear staining intensity or $11-50 \%$ of cells with nuclear staining; 2, moderate nuclear staining intensity and $>50 \%$ of cells with nuclear staining and 3 , strong nuclear staining intensity and $>50 \%$ of cells with nuclear staining. Sections were scored independently by two investigators (T.K. and L.N.) blinded to the patients' clinical profile.

\section{Quantification of histologic injury in human renal biopsies}

The human renal biopsy specimens were reviewed and analyzed by an independent anatomic pathologist who was blinded to the quantification of $\mathrm{pSmad} 2 / 3$ and $\mathrm{p} 300$ immunostaining. The severity of glomerulosclerosis was expressed as the percentage of globally sclerosed glomeruli out of the total number of glomeruli in the renal biopsy. The nonglobally sclerosed glomeruli were analyzed for the presence of proliferative segmental lesions, crescents, microadhesions, and segmental (or global) sclerotic lesions. The degree of interstitial inflammation, interstitial fibrosis and tubular atrophy was scored between 0 and 3 according to the following: $\mathbf{0}, 0$ to $5 \% ; 1,6$ to $20 \% ; 2,21$ to $40 \%$; and $3,>40 \%$ of the biopsy area demonstrating inflammation, fibrosis or atrophy, respectively. A previously described morphometric analysis based on point counting was used [25].

\section{Statistical analyses}

Data are presented as mean \pm 1 standard deviation. Comparisons between the groups were made with the Kruskal-Wallis test. Mann-Whitney U test was used to compare the molecules' expression between normal controls and every form of GN. The Spearman correlation analysis was used to detect possible correlations between staining scores at various nephron sites, clinical data and indices of histologic injury. The association of $\mathrm{pSmad} 2 / 3$ with p300 expression in glomerular lesions of serial sections was assessed with $\chi^{2}$ test. Statistical significance was set at $5 \%$.

\section{Results}

\section{Smad2/3 activation in normal human kidney}

Within normal human kidney a small number of cells within the glomerulus $(<10 \%$ of total glomerular cells) were $\mathrm{pSmad} 2 / 3$ positive, including podocytes, mesangial, endothelial as well as parietal epithelial cells. All tubular segments (proximal, distal and collecting) were stained for $\mathrm{pSmad} / 3$, exhibiting though a weak staining (Fig. 1a). The staining pattern was nuclear as expected from in vitro studies demonstrating that phosphorylation of Smad2/3 leads to their translocation from the cytoplasm to the nucleus where they exert their effects [26].

\section{p300 expression in normal human kidney}

Less than $30 \%$ of glomerular cells were p300 positive, including all cell types. Proximal tubular cells were either negative or weakly stained. Distal tubular cells as well as collecting tubules were constantly p300 positive with a moderate to strong staining intensity (Fig. $1 \mathrm{~b}$ and $1 \mathrm{c}$ ). The staining pattern was nuclear as expected from previous immunohistochemical studies in other tissues [27]. 


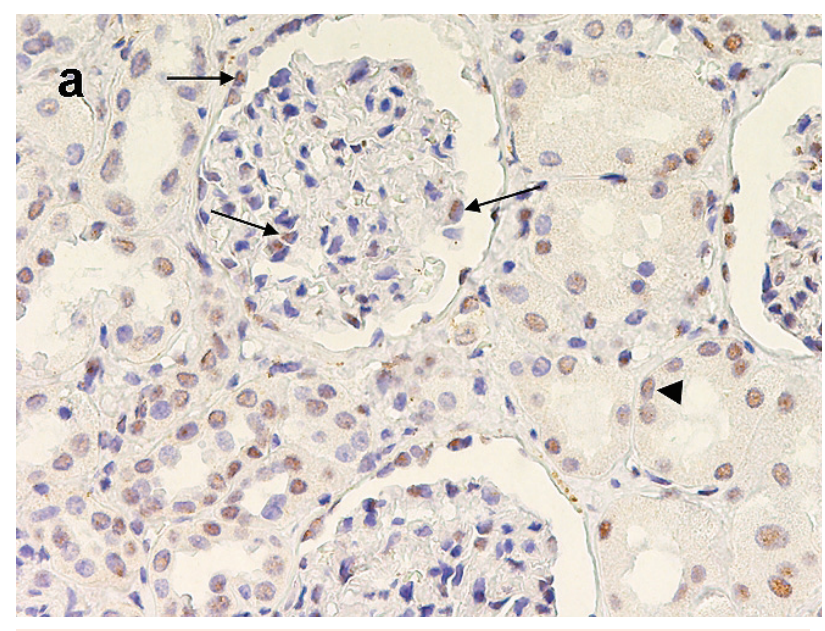

Fig. 1 pSmad2/3 and p300 expression in normal human kidney. (a) A small number of cells within the glomerulus were $\mathrm{pSmad} / 3$ positive, including podocytes, mesangial, endothelial as well as parietal epithelial cells (arrows). All tubular segments were stained for $\mathrm{pSmad} / 3$, exhibiting though a weak staining (arrowhead). (b) A few glomerular cells were p300 positive, including all cell types (arrows). (c) Proximal tubular cells (arrow) were either negative or weakly stained, while distal (arrowhead) and collecting tubules were constantly p300 positive. Original magnification $\times 400$.

\section{pSmad2/3 and p300 expression in human glomerulonephritis}

There was a dramatic increase in the expression of $\mathrm{pSmad} 2 / 3$ and p300 in all glomerular cell types in both proliferative and nonproliferative glomerulonephritides $(p<0.0005)$ (Fig. 2a). Proliferative glomerulopathies exhibited an increased $\mathrm{pSmad} 2 / 3$ expression in glomeruli $(\mathrm{p}<0.001)$ and all tubular segments $(p=0.003, p=0.015$ and $p=0.025$ for proximal, distal and collecting tubules respectively) and an increased p300 immunopositivity in glomeruli $(\mathrm{p}=0.005)$ and proximal tubules $(\mathrm{p}<$ 0.0005 ) compared to nonproliferative GNs (Table 2). The expression of both molecules was more intense in the secondary group of proliferative GNs (Table 3). Similar immunostaining results were obtained comparing the nonproliferative group with the control group except for the fact that there was no difference in $\mathrm{pSmad} 2 / 3$ expression in proximal tubules $(\mathrm{p}=0.228)$. In particular, only pauci-immune and

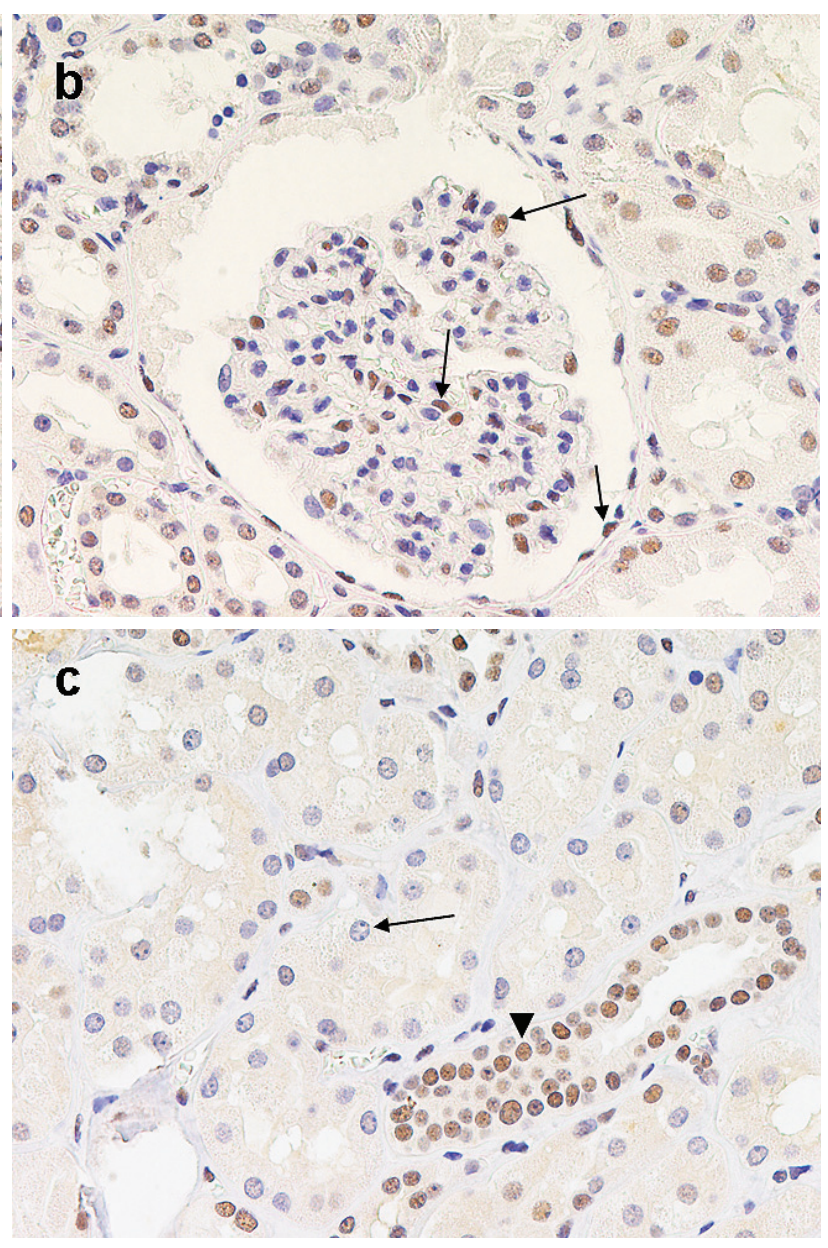

lupus proliferative nephritis exhibited an increased $\mathrm{pSmad} 2 / 3$ expression in proximal tubules $(\mathrm{p}=0.001$ and $p=0.003$ respectively) (Fig. 2b). Taking into account all GNs, secondary glomerulopathies exhibited an increased $\mathrm{pSmad} 2 / 3$ and $\mathrm{p} 300$ expression in glomeruli $(\mathrm{p}<0.0005$ and $\mathrm{p}=0.015$ respectively $)$ and proximal tubules $(p=0.002$ and $p=0.004$ respectively) compared to primary GNs. Compared to control no difference was detected in the expression of p300 in distal and collecting tubules of specimens with GN (Fig. 2c and 2d).

Comparisons between the different types of GN with the Kruskal-Wallis test showed a statistically significant difference in the expression of $\mathrm{pSmad} 2 / 3$ and $\mathrm{p} 300$ in glomeruli and proximal tubules $(\mathrm{p}<0.0005, \mathrm{p}=0.04$ and $\mathrm{p}=0.015, \mathrm{p}=$ 0.001 respectively). In detail, $\mathrm{pSmad} 2 / 3$ exhibited an increased glomerular expression in Pauci-Im GN compared with MCD, MGN, FSGS, and non-proliferative lupus nephritis (NPLN) and in proliferative lupus nephritis (PLN) compared with FSGS and an 

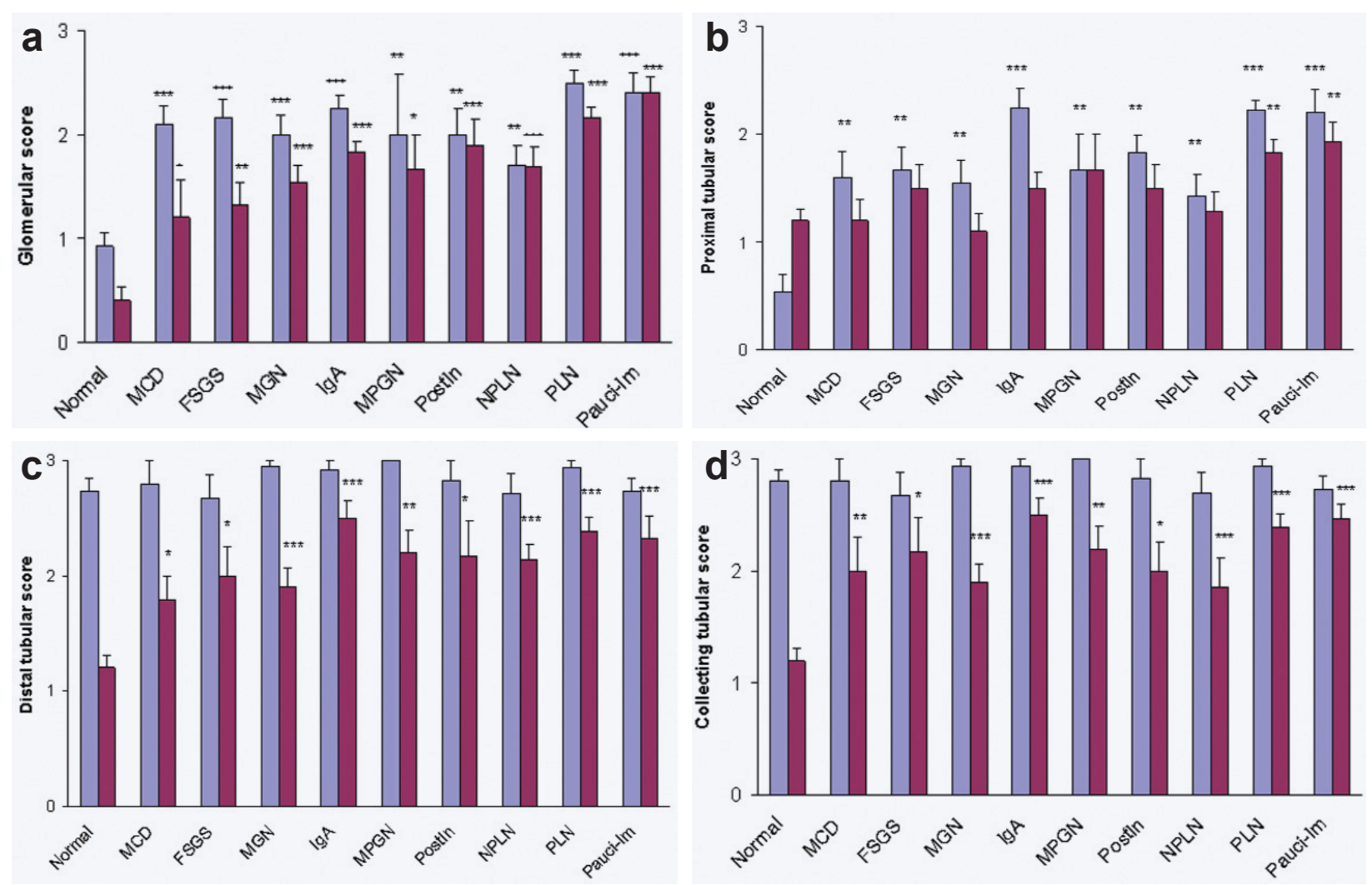

Fig. 2 Glomerular (a), proximal tubular (b), distal tubular (c) and collecting tubular (d) staining scores of p300 ( $\square)$ and pSmad2/3 ( $\square$ ) in normal and diseased human kidneys. The error bars represent SE. *: $\mathrm{P}<0.05$, $* *$ : $\mathrm{P}<0.01, * * *: \mathrm{P}<0.001$. For abbreviations see legend to Table 1 .

increased proximal tubular expression in Pauci-Im GN compared with MCD. Similarly, p300 glomerular expression was more intense in Pauci-Im GN and PLN compared with NPLN while its proximal tubular expression was increased in Pauci-Im GN compared with MGN, FSGS and NPLN.

With regard to pathologic lesions p300 and $\mathrm{pSmad} 2 / 3$ were almost constantly expressed in segmental hyperplastic lesions (100\% and $97 \%$ respectively) (Fig. 3a and 3b), cellular and fibrocellular crescents (98\% and 97\% respectively) (Fig. 3c and $3 d)$ and microadhesions ( $92 \%$ and $87 \%$ respectively) (Fig. 3e and 3f), while they were frequently detected in sclerotic glomeruli $80 \%$ and $79 \%$ for p300 and $63 \%$ and $73 \%$ for pSmad $2 / 3$ for segmentally or globally sclerosed glomeruli respectively) (Fig. 3g-j, Table 4). In cells overlying the sclerotic segments the expression of both molecules was prominent (Fig. $3 \mathrm{~g}$ and $3 \mathrm{~h}$ ). There was a statistically significant association in the expression of both molecules in serial sections of glomeruli with microadhesions and segmental sclerosis (Fisher's exact test, $\mathrm{p}=0.001$ and $\mathrm{p}=0.015$ respectively). Chi square test in respective cases with segmental hyperplasia or cellular crescents could not be performed due to impotence of the method (all serial sections with segmental hyperplasia and $90 \%$ of serial sections with cellular crescents were both positive for $\mathrm{p} 300$ and $\mathrm{pSmad} 2 / 3$ ).

\section{Correlation of pSmad2/3 with p300 expression at correspondent nephron sites - Correlations between immunohistochemical, clinical, and histologic parameters}

Taking into account all glomerulonephritides, there was a positive correlation between the expression profile of pSmad2/3 and p300 in diseased glomeruli and proximal tubular cells $(r=0.357, p$ $<0.0005$ and $\mathrm{r}=0.259, \mathrm{p}=0.01$ ) (Table 5). Moreover, pSmad2/3 and p300 glomerular and 
Table 2 Comparison of $\mathrm{pSmad} 2 / 3$ and $\mathrm{p} 300$ staining intensity in proliferative vs nonproliferative GNs

\begin{tabular}{|c|c|c|c|c|c|}
\hline & & \multicolumn{4}{|c|}{ Staining Score } \\
\hline & & pSmad2/3 & $P$ & P300 & $P$ \\
\hline \multirow{2}{*}{ Glomerulus } & Proliferative & $2.03 \pm 0.61$ & $<0.0005$ & $2.28 \pm 0.65$ & 0.005 \\
\hline & Nonproliferative & $1.51 \pm 0.61$ & & $1.98 \pm 0.54$ & \\
\hline \multirow{2}{*}{$\begin{array}{c}\text { Proximal } \\
\text { tubules }\end{array}$} & Proliferative & $1.76 \pm 0.67$ & 0.003 & $2.12 \pm 0.64$ & $<0.0005$ \\
\hline & Nonproliferative & $1.40 \pm 0.61$ & & $1.54 \pm 0.60$ & \\
\hline \multirow{2}{*}{ Distal tubules } & Proliferative & $2.39 \pm 0.59$ & 0.015 & $2.82 \pm 0.41$ & 0.869 \\
\hline & Nonproliferative & $2.13 \pm 0.56$ & & $2.82 \pm 0.38$ & \\
\hline \multirow{2}{*}{$\begin{array}{l}\text { Collecting } \\
\text { tubules }\end{array}$} & Proliferative & $2.39 \pm 0.60$ & 0.025 & $2.85 \pm 0.36$ & 0.433 \\
\hline & Nonproliferative & $2.14 \pm 0.63$ & & $2.79 \pm 0.41$ & \\
\hline
\end{tabular}

Staining scores are presented as mean \pm 1 standard deviation.

Table 3 Comparison of pSmad2/3 and p300 staining intensity in secondary vs primary proliferative GNs

\begin{tabular}{|c|c|c|c|c|c|}
\hline & \multirow{2}{*}{ Proliferative GN } & \multicolumn{4}{|c|}{ Staining Score } \\
\hline & & pSmad2/3 & $P$ & P300 & $P$ \\
\hline \multirow{2}{*}{ Glomerulus } & Secondary & $2.24 \pm 0.58$ & $<0.0005$ & $2.41 \pm 0.62$ & 0.025 \\
\hline & Primary & $1.72 \pm 0.53$ & & $2.07 \pm 0.65$ & \\
\hline \multirow{2}{*}{$\begin{array}{c}\text { Proximal } \\
\text { tubules }\end{array}$} & Secondary & $1.93 \pm 0.63$ & 0.009 & $2.22 \pm 0.64$ & 0.096 \\
\hline & Primary & $1.50 \pm 0.64$ & & $1.96 \pm 0.64$ & \\
\hline \multirow{2}{*}{ Distal tubules } & Secondary & $2.42 \pm 0.59$ & 0.623 & $2.83 \pm 0.39$ & 0.780 \\
\hline & Primary & $2.34 \pm 0.61$ & & $2.82 \pm 0.48$ & \\
\hline \multirow{2}{*}{$\begin{array}{l}\text { Collecting } \\
\text { tubules }\end{array}$} & Secondary & $2.45 \pm 0.50$ & 0.426 & $2.80 \pm 0.40$ & 0.176 \\
\hline & Primary & $2.29 \pm 0.71$ & & $2.92 \pm 0.27$ & \\
\hline
\end{tabular}

Staining scores are presented as mean \pm 1 standard deviation.

proximal tubular immunostaining correlated positively with interstitial inflammation $(r=0.243, p=$ $0.007, \mathrm{r}=0.304, \mathrm{p}=0.001$ for $\mathrm{p} 300$ and $\mathrm{r}=0.193$, $\mathrm{p}=0.043, \mathrm{r}=0.223, \mathrm{p}=0.02$ for $\mathrm{pSmad} 2 / 3$ respectively), while their expression in distal and collecting tubules exhibited a positive correlation with tubular atrophy $(\mathrm{r}=0.201, \mathrm{p}=0.022, \mathrm{r}=0.258, \mathrm{p}$
$=0.005$ for $\mathrm{p} 300$ and $\mathrm{r}=0.19,0=0.042, \mathrm{r}=0.203$, $\mathrm{p}=0.032$ for $\mathrm{pSmad} 2 / 3$ respectively). Finally, the expression of $\mathrm{pSmad} 2 / 3$ in the diseased glomeruli and proximal tubules correlated positively with serum creatinine values of the correspondent patients $(\mathrm{r}=0.334, \mathrm{p}=0.004$ and $\mathrm{r}=0.356, \mathrm{p}=$ 0.002 respectively) (Table 6). 


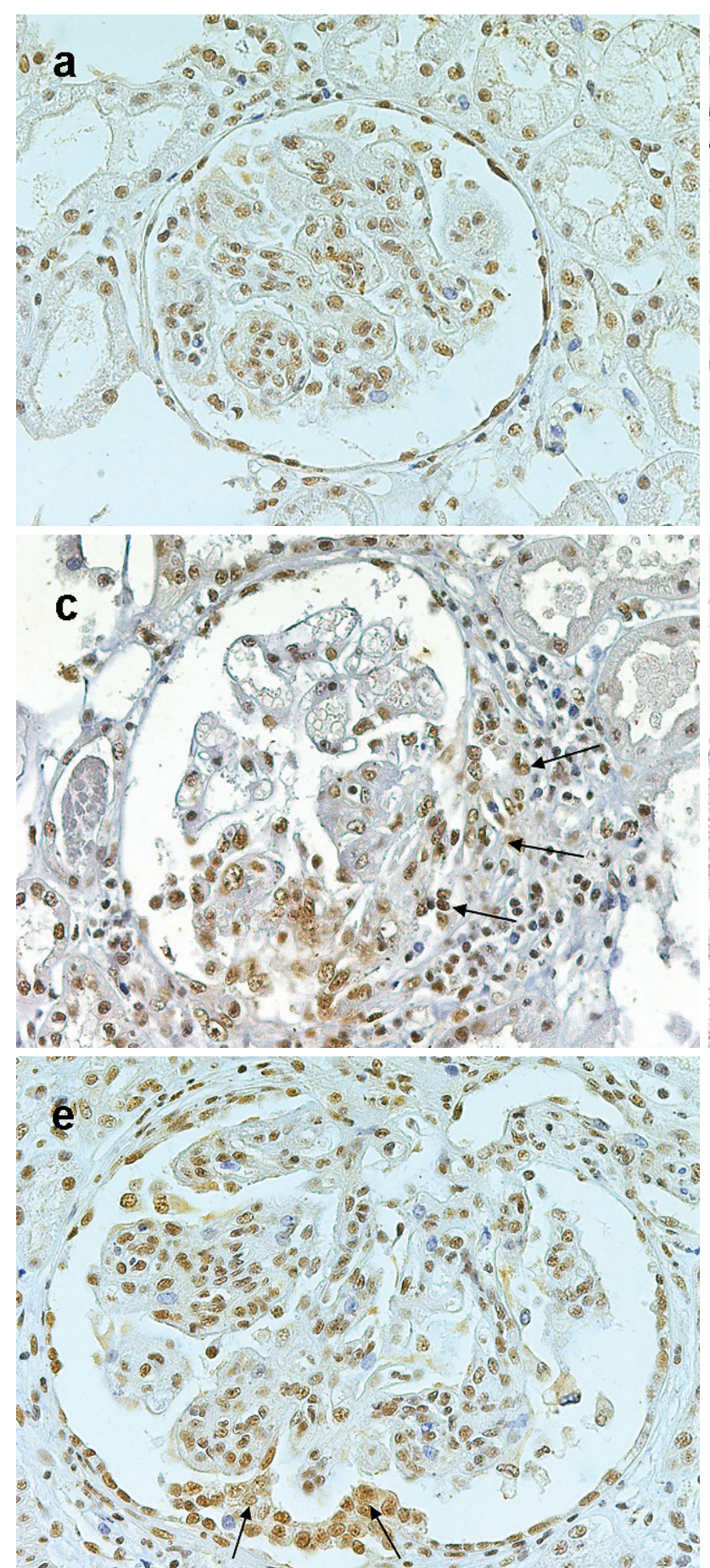

However, subgroup analysis revealed that this correlation stood only for nonproliferative glomerulonephritides $(r=0,406, p=0.021$ and $r=0.433, p=0.013$ ). Moreover, the expression of p300 in distal and collecting tubules exhibited a positive correlation with tubular atrophy only in the proliferative group $(\mathrm{r}=0.304, \mathrm{p}=$ 0.01 and $\mathrm{r}=0.27, \mathrm{p}=0.01) . \mathrm{pSmad} 2 / 3$

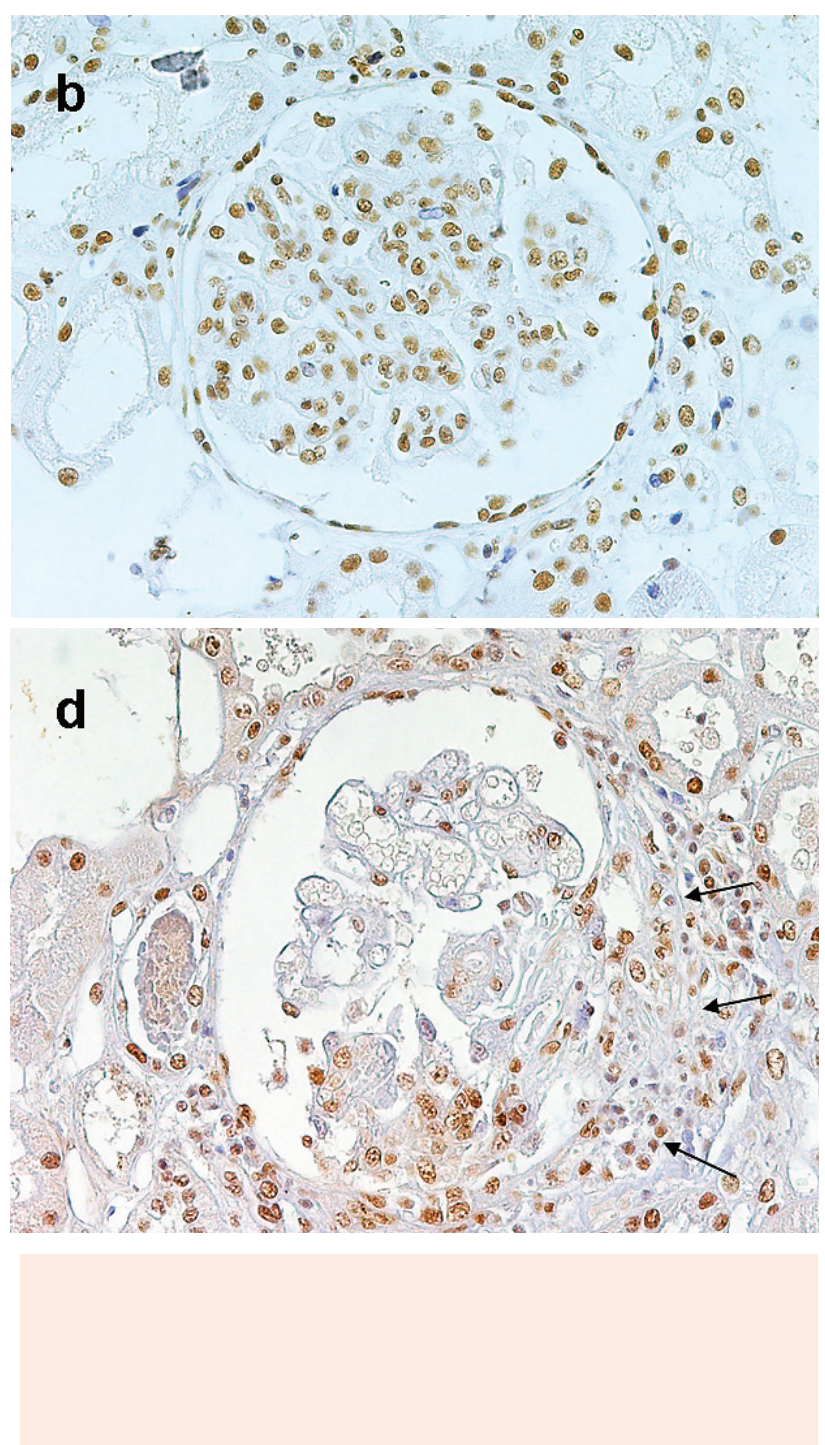

Fig.3 Serial sections from various cases with glomerulonephritis exhibiting pSmad2/3 (a, c, e, $\mathbf{g}, \mathbf{i})$ and p300 (b, $\mathbf{d}, \mathbf{f}, \mathbf{h}, \mathbf{j})$ immunopositivity in: hyperplastic lesions (proliferative lupus nephritis, WHO class IV) (a and b), a cellular crescent

glomerular and proximal tubular expression as well as p300 glomerular expression correlated positively with lupus nephritis activity $(\mathrm{r}=$ $0.45, p=0.03, r=0.47, p=0.011$ and $r=0.618$, $\mathrm{p}=0.042$ respectively). No correlation was detected between the expression of the two molecules with 24-hour urinary protein or interstitial fibrosis (Table 6). 


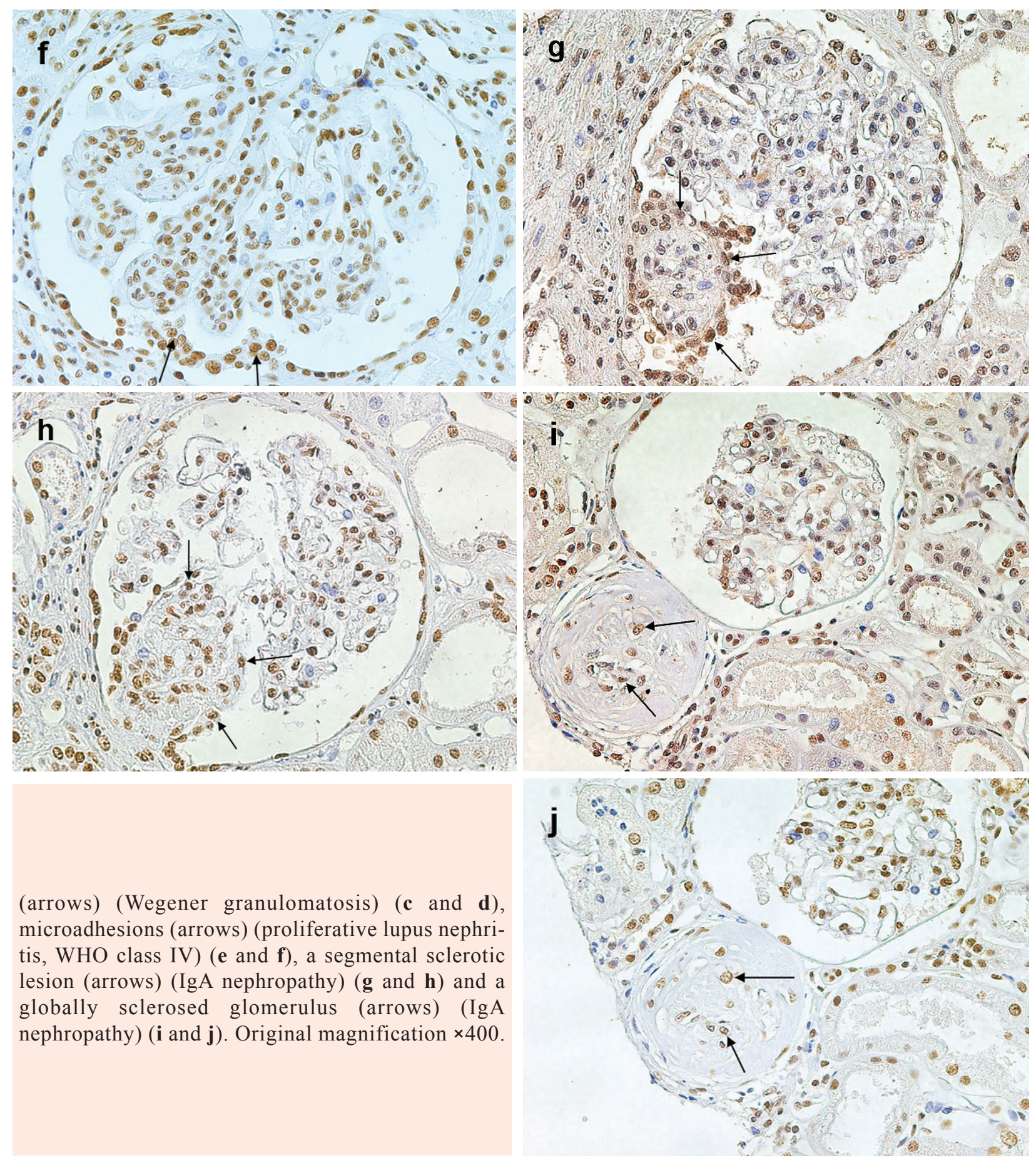

\section{Discussion}

In this study, the activation of the transcription factors $\operatorname{Smad} 2 / 3$ and the expression of the coactivator p300 in normal human kidney and in specimens from patients with various forms of GN were examined.

A previous study on human renal tissue reported no immunostaining for $\mathrm{pSmad} 2 / 3$ in normal specimens [21]. These results contrast with the findings of the current study. This divergence is most likely due to differences in the immunostaining protocol or the usage of a different primary antibody. Specifically, Kim et al. baked sections in a microwave oven for 5 minutes, incubated the sec- 
Table 4 The percentages of p300/pSmad2/3 immunopositivity incidence in the various lesions of the different groups of GN

\begin{tabular}{ccccccc}
\hline & \multicolumn{5}{c}{ Glomeruli } \\
\cline { 2 - 7 } & $\begin{array}{c}\text { Total } \\
\text { number of } \\
\text { cases }\end{array}$ & $\begin{array}{c}\text { Segmental } \\
\text { hyperplasia }\end{array}$ & $\begin{array}{c}\text { Cellular } \\
\text { crescents }\end{array}$ & $\begin{array}{c}\text { Micro- } \\
\text { adhesions }\end{array}$ & $\begin{array}{c}\text { Segmental } \\
\text { sclerosis }\end{array}$ & $\begin{array}{c}\text { Global } \\
\text { sclerosis }\end{array}$ \\
\hline $\begin{array}{c}\text { Non-proliferative } \\
\text { primary GNs } \\
\text { Non-proliferative }\end{array}$ & 49 & 18 & $70 \% / 70 \%$ & $71 \% / 60 \%$ & $82 \% / 70 \%$ \\
$\begin{array}{c}\text { SLE GNs } \\
\text { Proliferative } \\
\text { primary GNs }\end{array}$ & 37 & $100 \% / 100 \%$ & $100 \% / 100 \%$ & $91 \% / 78 \%$ & $90 \% / 67 \%$ & $71 \% / 67 \%$ \\
$\begin{array}{c}\text { Proliferative } \\
\text { secondary GNs }\end{array}$ & 48 & $100 \% / 96 \%$ & $97 \% / 96 \%$ & $97 \% / 94 \%$ & $78 \% / 62 \%$ & $80 \% / 78 \%$ \\
\hline \begin{tabular}{c} 
All GNs \\
\hline
\end{tabular} & 152 & $100 \% / 97 \%$ & $98 \% / 97 \%$ & $92 \% / 87 \%$ & $80 \% / 63 \%$ & $79 \% / 73 \%$ \\
\hline
\end{tabular}

tions with the primary antibody at a dilution of 1 in 1000 and used an avidin-biotin-peroxidase method for antibody localization. In our study sections were baked for 15 minutes, the primary antibody was used at a dilution of 1 in 500 and a biotin free, twostep, HRP-labelled detection system was used for antibody localization. This system has been reported to have in many instances greater sensitivity than the avidin-biotin system [28, 29]. Regarding animal studies, it has been demonstrated that Smad 2 and 3 are weakly expressed in glomeruli and tubules in the 15-day mouse embryo [30]. In another study, they were detected at all embryonic and postnatal stages examined, including the adult mouse kidney [31]. TGF- $\beta 1$ (whose signals are mostly mediated by Smad2/3) and its receptors are expressed in all glomerular cell types as well as in tubular cells in the rat kidney [32]. Furthermore, previous reports have shown that TGF- $\beta$ has an impact on tubular function [33, 34]. Thus, it is possible that Smad2 and Smad3 are important factors for structural and functional homeostasis in the nephron, although their physiological functions in the kidney are not well understood.

p300 expression in mouse mesangial cells has been documented in a previous study [22]. However, no data exist on its expression in normal or diseased human kidneys. p300 is a transcriptional "integrator" involved in a wide range of cellular activities, such as DNA repair, cell growth, differentiation, and apoptosis [35]. Thus, its expression in normal glomerular, distal and collecting tubular

Table 5 Correlation of pSmad2/3 with p300 expression at correspondent nephron sites

\begin{tabular}{cccc}
\hline Glomerulus & Proximal tubules & Distal tubules & Collecting tubules \\
\hline All/NP/P & All/NP/P & All $/ \mathrm{NP} / \mathrm{P}$ & All $/ \mathrm{NP} / \mathrm{P}$ \\
$0.357^{* * *} / 0.228 / 0.254^{*}$ & $0.259^{* * / 0.275 / 0.083}$ & $0.11 / 0.042 / 0.123$ & $0.183 / 0.163 / 0.142$ \\
\hline
\end{tabular}

The pSmad2/3 immunohistochemical staining score was correlated with p300 staining score at correspondent nephron sites using the Spearman single correlation coefficient. All: All glomerulonephritides, NP: nonproliferative GN, P: proliferative GN; $*: \mathrm{P}<0.05, * *: \mathrm{P}<0.01, * * *: \mathrm{P}<0.001$. 
Table 5 Correlations between immunohistochemical, clinical, and histologic parameters

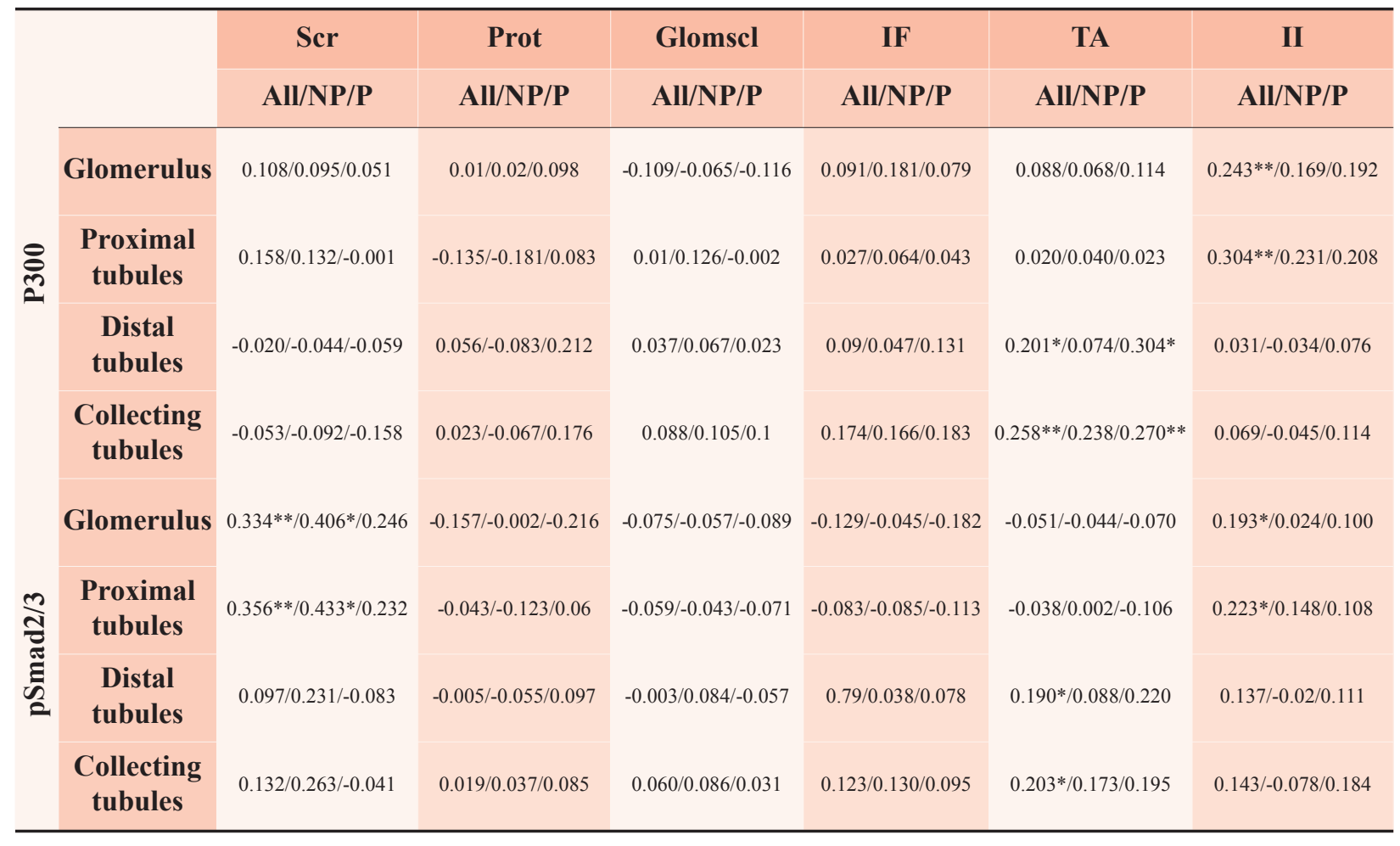

The immunohistochemical staining score at various nephron sites was compared with clinical data (serum creatinine levels and 24-hour urinary protein) and indices of histologic injury, using the Spearman single correlation coefficient in all glomerulonephritides (All), nonproliferative GN (NP) and proliferative GN (P). Values are given as $\mathrm{r} ; *$ : $\mathrm{P}<0.05, * *$ : $\mathrm{P}<0.01, * * *$ : $\mathrm{P}<0.001$. Scr: Serum creatinine, Prot: 24 -hour urinary protein, glomscl: glomerulosclerosis, IF: interstitial fibrosis, TA: tubular atrophy, II: interstitial inflammation. (Some Spearman $\mathrm{r}$ values in the All GNs column have superior P-values than corresponding higher $r$ values in NP GNs column. This is due to the larger amount of All GNs).

cells in our study suggests a potential role for $\mathrm{p} 300$ in maintaining the normal function of these cells.

This study provides the first demonstration of Smad2/3 activation and $\mathrm{p} 300$ overexpression in a broad spectrum of human glomerulonephritides. Although the activation of $\operatorname{Smad} 2 / 3$ is supposed to exert antiproliferative effects [36], in this study $\mathrm{pSmad} 2 / 3$ exhibited a more intense expression in proliferative GNs, particularly in the secondary group. However, this finding is in context with an earlier study demonstrating that glomerular TGF$\beta 1$ expression was more severe in proliferative compared to nonproliferative GNs [6]. Moreover, although TGF- $\beta$ in the initial phases of tumorigenesis acts as a tumor suppressor, in late stage tumors, it has been shown to act as a tumor promoter [37]. Smads, like TGF- $\beta$, depending on cellular context, may thus exert proliferative or antiproliferative effects [38]. Similarly, although several lines of evidence suggests that $\mathrm{p} 300$ is a negative regulator of the cell cycle [39, 40], its ability to serve also as mediator of cell proliferation remains a paradox [41]. Moreover, the increased expression of $\mathrm{pSmad} 2 / 3$ and p300 in glomeruli as well as in tubules of proliferative GNs and particularly of the secondary group may be due to the increased inflammation that accompanies the disease process. This is supported by the positive correlation of pSmad2/3 and p300 glomerular and proximal tubular immunostaining with interstitial inflammation. Except for its pro-fibrotic effect TGF- $\beta$ is also known to possess anti-inflammatory and immunoregulatory properties [23]. It is involved in the resolution of renal injury in the anti-Thy1 model of GN [42]. TGF- $\beta$ also exerts its anti-inflammatory effect by counteracting inflammatory cytokine pro- 
duction and by inhibiting IL- $1 \beta$ and TNF- $\alpha$ induced NF $\kappa B$ activation [43]. Exactly how TGF- $\beta$ regulates the immune response remains poorly understood, but Smad3 may play a critical role in immune-regulation by TGF- $\beta$ [44-46]. On the other hand, p300 except for its recruitment by Smad complexes it is also implicated in the NFKB signaling pathway by engaging to the activated $\mathrm{p} 65$ subunit [47]. NFKB is a transcription factor that plays an important role in the transcriptional regulation of genes involved in inflammation. Previous studies have shown that NFKB is activated in tubules and glomeruli in various experimental models of renal injury $[48,49]$. Thus, there might be a more intense Smad2/3 activation and p300 expression in conditions associated with increased inflammation.

In segmental hyperplastic lesions as well as in cellular and fibrocellular crescents which are hyperplastic lesions composed of epithelial cells and macrophages, pSmad2/3 as well as p300 immunopositivity was prominent. Based on the considerations made above the increased expression of these molecules in these lesions may either imply a potential mitogenic influence of these factors in cells forming cellular crescents or it may be due to the amplified inflammatory status and the subsequent release of cytokines (such as TGF- $\beta$ ), that accompanies the crescent formation process.

The common expression of $\mathrm{pSmad} 2 / 3$ and $\mathrm{p} 300$ in microadhesions may imply a role of these two molecules in the early stages of glomerulosclerosis. The statistical significant association in the expression of both molecules in serial sections of glomeruli with microadhesions and segmental sclerotic lesions suggests a possible recruitment of p300 by pSmad $2 / 3$ in these lesions in order to activate the transcription of genes responsible for glomerulosclerosis. As far as the chronic phase of glomerular injury is concerned, sclerotic glomeruli were almost constantly p300 positive, whereas pSmad2/3 immunopositivity was frequently detected. This suggests a possible role for these two molecules in advanced fibrotic events. This is the first study to demonstrate the colocalization of p300 and pSmad2/3 in early and advanced sclerotic lesions.

The positive correlation of glomerular and proximal tubular $\mathrm{pSmad} 2 / 3$ with the severity of renal dysfunction along with the positive correlation of pSmad2/3 and p300 with tubular atrophy in distal and collecting tubules may imply a role of these molecules in the progression of renal disease. This is also supported by the positive correlation of glomerular and proximal tubular $\mathrm{pSmad} 2 / 3$ and glomerular p300 with lupus nephritis activity and the increased expression of both molecules in glomeruli and proximal tubules of severe forms of GNs such as Pauci-IM GN and PLN. Moreover, the positive correlation of $\mathrm{pSmad} 2 / 3$ with $\mathrm{p} 300$ immunopositivity in the diseased glomeruli and proximal tubules along with their common expression at sites of microadhesions, cellular crescents, segmental hyperplastic and sclerotic lesions, argues that these molecules cooperate in inducing renal injury. Interestingly, it has been recently demonstrated that p300 is an essential component of the cellular TGF- $\beta$ signal transduction pathways mediating stimulation of collagen synthesis in fibroblasts [50].

In summary, this study has identified the expression of $\mathrm{pSmad} 2 / 3$ and p300 in normal human kidney and a marked increase in their expression in various nephron sites in many forms of GN. The correlation of Smad2/3 activation and p300 with clinical and histologic parameters suggests that this pathway plays an important role in the pathogenesis and the progression of human GN. Thus, blockade of $\mathrm{Smad} 2 / 3$ activation or $\mathrm{pSmad} 2 / 3$-p300 interaction may provide a novel target in the treatment of human GN. The latter treatment would have the potential of inducing minimal side effects as this interaction seems to be one of the late steps in the Smad signaling pathway.

\section{References}

1. Moses HL, Yang EY, Pietenpol JA. TGF-beta stimulation and inhibition of cell proliferation: new mechanistic insights. Cell 1990; 19: 245-7.

2. Robert AB, Sporn MB. The transforming growth factor- $\beta$ s. In: Peptide Growth Factors and Their Receptors, edited by Sporn MB, Robert AB, Berlin, Springer-Verlag, 1991, pp 419-472.

3. Eddy AA. Molecular basis of renal fibrosis. Pediatr Nephrol. 2000;15: 290-301.

4. Border WA, Noble NA. TGF-beta in kidney fibrosis: A target for gene therapy. Kidney Int. 1997; 51: 1388-96.

5. Böttinger EP, Bitzer M. TGF- $\beta$ signaling in renal disease. J Am Soc Nephrol. 2002; 13: 2600-10.

6. Yamamoto T, Noble NA, Cohen AH, Nast CC, Hishida A, Gold LI, Border WA. Expression of transforming 
growth factor-beta isoforms in human glomerular diseases. Kidney Int. 1996; 49: 461-9.

7. Blobe GC, Schiemann WP, Lodish HF. Role of transforming growth factor- $\beta$ in human disease. $N \mathrm{Engl} \mathrm{J} \mathrm{Med}$. 2000; 342: 1350-8.

8. Wrana JL, Attisano L, Wieser R, Ventura F, Massague J. Mechanism of activation of the TGF- $\beta$ receptor. Nature 1994; 370: 341-7.

9. Nakao A, Imamura T, Souchelnytskyi S, Kawabata M, Ishisaki A, Oeda E, Tamaki K, Hanai J, Heldin CH, Miyazono K, ten Dijke P. TGF- $\beta$ receptor-mediated signalling through Smad2, Smad3 and Smad4. EMBO J. 1997; 16: 5353-62.

10. Miyazono K, ten Dijke P, Heldin C-H. TGF- $\beta$ signaling by Smad proteins. Adv Immunol. 2000;75: 115-57.

11. Macias-Silva M, Abdollah S, Hoodless PA, Pirone R, Attisano L, Wrana JL. MADR2 is a substrate of the TGF- $\beta$ receptor and its phosphorylation is required for nuclear accumulation and signaling. Cell 1996; 87: 1215-24.

12. Zhang Y, Feng X-H, Wu RY, Derynck R. Receptor-associated Mad homologues synergize as effectors of the TGF$\beta$ response. Nature 1996; 383: 168-72.

13. Dennler S, Itoh $\mathbf{S}$, Vivien $\mathbf{D}$, ten Dijke $\mathbf{P}$, Huet $\mathbf{S}$, Gauthier JM. Direct binding of Smad3 and Smad4 to critical TGF- $\beta$-inducible elements in the promoter of human plasminogen activator inhibitor-type I gene. EMBO J 1998; 17: 3091-3100.

14. Zawel L, Dai JL, Buckhaults P, Zhou S, Kinzler KW, Vogelstein B, Kern SE. Human Smad3 and Smad4 are sequence-specific transcription activators. Mol Cell. 1998; 1: 611-17.

15. Massague J, Wotton $\mathbf{D}$. Transcriptional control by TGF$\beta /$ Smad signaling. EMBO J. 2000; 19: 1745-54.

16. Shi Y, Massague J. Mechanisms of TGF- $\beta$ signaling from cell membrane to the nucleus. Cell 2003; 113: 685-700.

17. de Caestecker MP, Yahata T, Wang D, Parks WT, Huang S, Hill CS, Shioda T, Roberts AB, Lechleider RJ. The Smad4 activation domain (SAD) is a proline-rich, p300-dependent transcriptional activation domain. J Biol Chem. 2000; 275: 2115-22.

18. Shen X, Hu PP, Liberati NT, Datto MB, Frederick JP, Wang XF. TGF-beta-induced phosphorylation of Smad3 regulates its interaction with co-activator p300/CREBbinding protein. Mol Biol Cell. 1998; 9: 3309-19.

19. Stroschein SL, Wang W, Zhou S, Zhou Q, Luo K. Negative feedback regulation of TGF-beta signaling by the SnoN oncoprotein. Science 1999; 286: 771-4.

20. Hong SW, Isono M, Chen S, Iglesias-De La Cruz MC, Han DC, Ziyadeh FN. Increased glomerular and tubular expression of transforming growth factor-beta1, its type II receptor, and activation of the Smad signaling pathway in the $\mathrm{db} / \mathrm{db}$ mouse. Am J Pathol 2001; 158: 1653-63.

21. Kim JH, Kim BK, Moon KC, Hong HK, Lee HS. Activation of the TGF-beta/Smad signaling pathway in focal segmental glomerulosclerosis. Kidney Int 2003; 64: 1715-21.

22. Kanamaru Y, Nakao A, Tanaka Y, Inagaki Y, Ushio H, Shirato I, Horikoshi S, Okumura K, Ogawa H, Tomino Y. Involvement of p300 in TGF-beta/Smad-pathway- mediated alpha2(I) collagen expression in mouse mesangial cells. Nephron Exp Nephrol. 2003; 95: e36-42.

23. Wang W, Koka V, Lan H. Transforming growth factor- $\beta$ and Smad signaling in kidney diseases. Nephrology 2005; 10: 48-56.

24. Bussolati G, Gugliotta P, Volante M, Pace M, Papotti M. Retrieved endogenous biotin: a novel marker and a potential pitfall in diagnostic immunohistochemistry. Histopathology 1997; 31: 400-7.

25. Williams MA, Lowrie JI. Fixation of tissue for morphometric study; in Bach FH, Lock EA (eds): Nephrotoxicity in experimental and clinical situations. Dordrecht, Martinus Nijhoff, 1987, part I, pp 141-66.

26. Li JH, Zhu HJ, Huang XR, Lai KN, Johnson RJ, Lan HY. Smad7 inhibits fibrotic effect of TGF-Beta on renal tubular epithelial cells by blocking $\operatorname{Smad} 2$ activation. $J \mathrm{Am}$ Soc Nephrol. 2002; 13: 1464-72.

27. Yamashita S. Ontogenic expression of estrogen receptor co-activators in the reproductive tract of female mice neonatally exposed to diethylstilbestrol. Reprod Toxicol 2004; 18: 275-84.

28. Vyberg M, Nielsen S. Dextran polymer conjugate twostep visualization system for immunohistochemistry. A comparison of EnVision+ with two three step avidinbiotin techniques. Appl Immunohistochem 1998; 61: 3-10.

29. Sabattini E, Bisgaard K, Ascani S, Poggi S, Piccioli M, Ceccarelli C, Pieri F, Fraternali-Orcioni G, Pileri SA. The EnVision ${ }^{\mathrm{TM}}+$ system: a new immunohistochemical method for diagnostics and research. Critical comparison with APAAP, ChemMateTM, CSA, LABC, and SABC techniques. J Clin Pathol. 1998; 51: 506-11.

30. Flanders K, Kim E, Roberts A. Immunohistochemical expression of Smads 1-6 in the 15-day gestation mouse embryo: signaling by BMPs and TGF-betas. Dev Dyn. 2001; 220: 141-54.

31. Vrljicak P, Myburgh D, Ryan AK. Smad expression during kidney development. Am J Physiol Renal Physiol. 2004; 286: F625-33.

32. Ando T, Okuda S, Yanagida T, Fujishima $M$. Localization of TGF-beta and its receptors in the kidney. Miner Electrolyte Metab. 1998; 24: 149-53.

33. Wolf G, Mueller E, Stahl RA, Ziyadeh FN. Angiotensin II-induced hypertrophy of cultured murine proximal tubular cells is mediated by endogenous transforming growth factor-beta. J Clin Invest. 1993; 92: 1366-72.

34. Law F, Rizzoli R, Bonjour JP. Transforming growth factor-beta inhibits phosphate transport in renal epithelial cells. Am J Physiol. 1993; 264: F623-8.

35. Goodman RH, Smolik S. CBP/p300 in cell growth, transformation and development. Genes Dev. 2000; 14: 1553-77.

36. Ten Dijke P, Goumans MJ, Itoh F, Itoh S. Regulation of cell proliferation by Smad proteins. J Cell Physiol. 2002; 191: 1-16.

37. Derynck R, Akhurst RJ, Balmain A. TGF-beta signaling in tumor suppression and cancer progression. Nat Genet. 2001; 29: 117-29.

38. de Caestecker MP, Piek E, Roberts AB. Role of transforming growth factor-beta signaling in cancer. $J$ Natl Cancer Inst. 2000; 92: 1388-402. 
39. Giordano A, Avantaggiati ML. p300 and CBP, partners for life and death. J Cell Physiol. 1999; 181: 218-30.

40. Iyer NG, Ozdag H, Caldas C. p300/CBP and cancer. Oncogene 2004; 23: 4225-31.

41. Debes JD, Sebo TJ, Lohse CM, Murphy LM, Haugen de AL, Tindall DJ. p300 in prostate cancer proliferation and progression. Cancer Res. 2003; 63: 7638-40.

42. Patel P, Varghese E, Ding G, Fan S, Kapasi A, Reddy K, Franki N, Nahar N, Singhal P. Transforming growth factor beta induces mesangial cell apoptosis through NO- and p53-dependent and -independent pathways. J Investig Med. 2000; 48: 403-10.

43. Hanada T, Yoshimura A. Regulation of cytokine signaling and inflammation. Cytokine Growth Factor Rev. 2002; 13: 413-21.

44. McCartney-Francis N, Jin W, Wahl SM. Aberrant Toll receptor expression and endotoxin hypersensitivity in mice lacking a functional TGF-beta 1 signaling pathway. J Immunol. 2004; 172: 3814-21.

45. McKarns SC, Schwartz RH, Kaminski NE. Smad3 is essential for TGF-beta 1 to suppress IL-2 production and TCR-induced proliferation, but not IL-2-induced proliferation. J Immunol. 2004; 172: 4275-84.
46. Feinberg MW, Shimizu K, Lebedeva M, Haspel R, Takayama K, Chen Z, Frederick JP, Wang XF, Simon DI, Libby P, Mitchell RN, Jain MK. Essential role for Smad3 in regulating MCP-1 expression and vascular inflammation. Circ Res. 2004; 94: 601-8.

47. Vanden Berghe W, Vermeulen L, Delerive P, De Bosscher K, Staels B, Haegeman G. A paradigm for gene regulation: inflammation, NF-kappaB and PPAR. $A d v$ Exp Med Biol. 2004; 544: 181-96.

48. Gomez-Garre D, Largo R, Tejera N, Fortes J, Manzarbeitia F, Egido J. Activation of NF-kappaB in tubular epithelial cells of rats with intense proteinuria: role of angiotensin II and endothelin-1. Hypertension 2001; 37: 1171-8.

49. Rangan GK, Wang Y, Tay YC, Harris DC. Inhibition of nuclear factor-kappaB activation reduces cortical tubulointerstitial injury in proteinuric rats. Kidney Int. 1999; 56: $118-34$.

50. Bhattacharyya S, Ghosh AK, Pannu J, Mori Y, Takagawa S, Chen G, Trojanowska M, Gilliam AC, Varga J. Fibroblast expression of the co-activator p300 governs the intensity of profibrotic response to transforming growth factor beta. Arthritis Rheum. 2005; 52: 1248-58. 